\title{
EFFECTS OF OFFICE SPACE AND COLOUR ON KNOWLEDGE SHARING AND WORK STRESS
}

\author{
Luke Hsiao
}

Department of Public Policy and Management, I-Shou University

Ming-Chi Hsiao

Department of Tourism Management, Taiwan Shoufo University

Yu-Lan Wang*

Kaohsiung Extension Education, Taiwan Shoufo University

\begin{abstract}
With the aid of empirical research, this study aims to verify the effects of the variables Office Space and Colour on Knowledge Sharing and Work Stress. Taking the domestic technology industry as the research sample, purposive sampling was applied in a questionnaire survey. Three hundred and sixty-eight questionnaires were distributed to a total of 14 technology companies in the Hsinchu and Southern Taiwan Science Parks. After 21 invalid responses had been removed, 347 valid copies were retrieved. Reliability analysis, factor analysis and hierarchical regression were used to analyse the data. The research outcomes show the significant effects of Office Space and Colour on Knowledge Sharing and Work Stress among employees. Based on the outcomes, certain conclusions and suggestions are proposed.
\end{abstract}

Key words: office space, colour, knowledge sharing, work stress, role conflict, role ambiguity, intention, organisation, technology industry, work load

JEL: M100

1

\section{Introduction}

Time magazine (2006) reported on the office design at Google where an office is a playground and the relaxing atmosphere is purposively designed to allow employees to take a nap at anytime and bring pets along, and the offices of some female employees look like toy shops. Chang and Han (2006) indicate that colour in an indoor environment could have a psychological effect on people's sense of wellbeing, balance, visual aesthetics and stability. With regard to the planning of office space, Harrar (1999) mentions the importance of places and conditions when it comes to knowledge sharing among the employees in an organisation. Numerous hierarchies have resulted in a lack of adaptation and flexibility, as the employees are arranged in a narrow area with a hierarchic gap across which communication has to take place. This is unfavourable for face-to-face exchanges and knowledge sharing. Employees at an enterprise should have a space for free exchange and open communication so as to reduce the cost of knowledge sharing. Independent research showed that offices were considered to be one of the three primary factors in job satisfaction (Heather, 2003) and therefore people should pay attention to the issue of office planning. Knowledge sharing does not automatically occur in an organisation. Hanson (2002) states that knowledge is asymmetricin an organisation where the knowledge flow depends on individual intention. With regard to behaviourism, it should be noted that personal traits, motives, cognition and environmental characteristics could all affect individual behaviours and intentions. Moreover, knowledge sharing is restricted as regards channels. An informal mechanism, a so-called pantry and chat room culture, refers to the knowledge exchange and sharing that is apparent when employees converse and chat in 
informal places. Moreover, in relation to the infra-structure of knowledge sharing capability and the sharing of confidences, the provision of a space for interaction and networking in a wide area influences the effectiveness of knowledge sharing. Kenneth and Julie Kendall (1981) pointed out the importance of position, space and colour in the physical environment of office design, stating that they could influence individual and organisational decisions. This study explores the benefits for knowledge sharing of designing a favourable office in an organisation with various colour and space compositions and further attempts to improve management and research methods.

\section{2}

\section{Literature review and research hypotheses}

\subsection{Office space}

Chang (1995) mentions, in Architectural and Environmental Psychology, that people at higher levels, such as chairmen of the board, bosses and managers, possess personal rooms, while section chiefs and the general staff are spread around a large room. In office design, the size of an individual's space is determined by hierarchy, egalitarianism and function (Downey, 2004). Office staff seem to have a psychological preference for small office spaces. From the perspective of interaction and work autonomy, Duffy, a British architect, classifies the interior office layout into hives, cells, dens and clubs (Chiang, 2000). In addition to individual work space, public space is incorporated into the working environment of the organisation as a whole. Public space does not simply provide sufficient meeting rooms or libraries for the staff to confer with each other. The public space as it relates to individual staff (such as a gym or a smoking room) could also help to promote job satisfaction and enhance staff cohesion. According to the 2003 investigation by Today magazine conducted in the UK, most British managers were not satisfied with their current workplaces and 53 per cent of them expected the companies to provide fitness equipment, 41 per cent indicated restaurants, and 27 per cent mentioned shower rooms. This is an indication that employees have certain demands for space that are unrelated to the job (Anonymous, 2003).

\subsection{Colour}

Kenneth and Julie Kendall (1981) suggested that using bright colours on walls in office design could encourage spontaneity and attention to work. Colour is a basic element of indoor form that not only creates visual perceptions but also reveals the actual functions of 1 . Personality presentation; 2 . Light regulation; 3 . Space adjustment; 4. Match of activities; and 5. Climate adaptation (Wang, 1993). With regard to space adjustment, Deng and Weng (1991) and Kuo (2006) propose colour conditions to create a comfortable space that would lend itself to a relaxed working environment. The aims of the use of colour are: 1. Select the correct lighting and appropriate colours to reduce unnecessary eye strain. 2. Maintain pleasant living conditions to enhance the desire to work. 3. Promote wellbeing by using colours to enhance security. Liu (2006) also states that a more comfortable and favourable interior environment could be created and work efficiency could be promoted by fully utilising colour. Some colours are strong (dark colours with high chroma), and others are light. Cold colours suggest tranquillity more than warm colours do. Pure colours are temperate and are suited to privacy and static activities. In contrast, colours which are strong and active correlate with groups and dynamic activities (Wang, 1993). Chiu (2012) discovered that demographic variables affect the participants' preferences. The commonest colours for office space appeared to be achromatic colours, shades of orange and shades of blue; men preferred achromatic colour, and women were in favour of shades of blue. In the face of the development of information technology and the emphasis on humane issues, colours also reflect mobility, dynamism and personalisation. The above literature revealed that the application of colour in the office affects the staff's work efficiency and the application of that demographic can influence colour preferences.

\subsection{Work stress}

Stressors, the cause of work stress, are the stimuli that cause a person to feel stress. Such 
stimuli may originate from interaction with other people, daily activities or individual inner thoughts (Lin \& Ensel, 1989). When a person experiences stress, he or she could face life in a positive manner, or he or she might become depressed, be unable to deal with the stimuli which destroyed the harmony in life, and display abnormal psychological, physiological and behavioural states. Such stimuli, which cause individuals to perceive pressure, are regarded as stressors (Lai, 2001). With regard to the sources of work stress, Ivancevich and Matteson (1980) propose the following classification: 1 . Physical environment; 2 . Individual; 3. Group; 4. Within the organization; 5. Out of the organisation. According to the stress model proposed by Robbins (2001), stress could manifest as physiological symptoms, psychological symptoms or behavioural symptoms. Physiological symptoms include headaches and hypertension. Psychological symptoms cover anxiety, depression and reduced job satisfaction. Behavioural symptoms include changes in productivity, absences from work and resignation. Work stress manifests as extreme effects on individual physical health and the overall performance of an organisation. For individuals, discontentment, low self-esteem and anxiety are likely to be the psychological symptoms experienced, while headaches, raspiness, gastric acid, hypertension and heart attacks are the physiological manifestations (Chiu, 1994). Research findings have showed that the higher work stress of employees in hitech industries can worsen depression. Among the perceived sources of work stress, stress from physiological responses and psychological responses appeared the strongest, causing a reduction in well-being (Liu \& Wang, 2009; Lee, Chen \& Lai, 2012).

\subsection{Knowledge sharing intention}

Liu, Yung-lun (2003) defined knowledge sharing as the imparting and absorption of knowledge. Grant (1996) regarded knowledge diffusion as dependent on common knowledge in that the higher the level of common knowledge, the higher the knowledge sharing intention. Common knowledge was further divided into the following: 1. Common language; 2. Communication symbols; 3. Universal or special know-ledge; 4. The meaning of sharing; 5. The under- standing of the individual knowledge field. Grant (1996) investigated the exclusivity of knowledge and the knowledge diffusion channels that could be effectively used where capabilities and the intention to share know-ledge exist. In the past, knowledge was accumulated by the staff, but not systematically recorded. Even if written records were kept, retrieval was considered complex, which obstructed knowledge diffusion. Generally speaking, a company could diffuse individual knowledge to other members of staff through project teams and teamwork so as to enhance the knowledge sharing intention. Elsbach and Bechky (2007) suggest that office design could support the intention to share knowledge, and office space design could enhance social interaction between individuals and groups. Office decorating could improve the performance of organisational groups. As a result, office design affects knowledge sharing from the dual perspectives of people and organisations. Employees in positions where they exercised a high measure of control in hitech industries showed greater willingness to share knowledge, which revealed positive relations with organisational justice and work values (Chen, 2004; Hua, 2009).

\section{3}

\section{Research hypotheses}

An enormous space could create unnecessarily high operational costs for an organisation. With the industrial and commercial development of recent years, individual work stress has increased and heavier physiological and psychological workloads have affected work efficiency. Among the factors causing work stress, Ivancevich and Matteson (1980) point to physical working environments as one of the stress factors. Tang, Chen and Chen (2002) indicate that noise, inadequate lighting and crowded working space in a working environment could be sources of work stress and influence work efficiency. Accordingly, the following hypothesis is proposed:

\section{Hypothesis 1: Office Space has a significant effect on work stress}

On the basis of well-known behaviourist theories (theory of planning behaviour, TPB), Lin (2005) concludes that there are complicated 
factors such as environmental factors and infrastructure that affect sharing and when an organisation provides interactive space and venues this could also affect confidence in knowledge sharing capability. Hou (1984) conducted international research on work stress and classified the stressors into three dimensions, which included the physical working environment. On the basis of the above literature studies, the following hypothesis is further proposed:

Hypothesis 2: Office Spacehas notable effects on knowledge sharing intention

In terms of behaviourism, knowledge sharing intention could influence knowledge sharing behaviour, together with individual cognition, environmental characteristics and behavioral expectations, which would affect behavioural intentions (Lin, 2005). According to the stress model proposed by Robbins (2001), stress affects physiological, psychological, and behavioural symptoms, where psychological symptoms include anxiety, depression and lower job satisfaction. Behavioural symptoms include productivity change, absence from work and resignation. Lan (2000) conducted research related to the effects of stress on individuals and organisations that reported absenteeism, poor interpersonal interaction, a high turnover rate, low work efficiency, low morale, high accident rates and job dissatisfaction, all of which have an influence on an organisation. Work stress was shown to have negative effects on psychological functioning, behaviour and cognition (Lan, 2000). The following hypothesis is further proposed:

Hypothesis 3: Work Stress shows remarkable effects on knowledge sharing intention

Regarding interior design, Liu (2006) suggests that finding the right colour-temperature could help fine-tune the design of a space with a specific atmosphere, and colour distance would change the proportion of a space pattern. In an experiment he conducted Louis Cheskin recorded excitement, with increasing blood pressure and pulse rates, in a bright-red room and lost production with decreasing blood pressure and pulse rates in a cyan- coloured room, where feelings of depression and confusion were generated so that the work was not completed in time. The brightness in a yellow room tired the eyes, but there were no changes in blood pressure. Normal reactions were recorded in a green room. However, the monochromatic green colour was rather dull and lifeless and some stimulation was found to be necessary (Hiroshi Ohchi, 1991). Some research also proved that being in a highchroma and high-brightness working environment could easily result in nervousness and an inability to relax. Chiu (2012) pointed out the effects of demographic variables on colour preferences. Accordingly, the following hypotheses are proposed in this study:

\section{Hypothesis 4: Colour appears to have anotable moderating effect on the relations between office space and work stress}

Lin (2005) mentions the effects of the environment factor on knowledge sharing intention. Chang and Han (2006) indicated that colour in an interior environment could have the psychological effect of triggering a pleasant sensation, balance and visual aesthetics, and represent stability, while different colours could cause distinct sensations, such as tranquillity, liveliness, pleasure, excitement, depression, coldness and warmth. Colour has two effects on interior design. (1) It could optimise a person's mental processes to enhance physiological functions. For instance, a person working in a room decorated in a cool colour appears to be more efficient than someone in a room done in a warm colour. (2) Colour can release spiritual and physical pain. In consequence, by carefully applying colour in interior design, it is possible to plan an excellent office and create a more favourable workplace so as to successfully share and diffuse knowledge. On the basis of the above literature, the following hypothesis is proposed:

Hypothesis 5: Colour has a significant moderating effect on the relation between office space and knowledge sharing. 
4

\section{Research method}

\subsection{Research framework}

\section{Figure 1}

Research framework

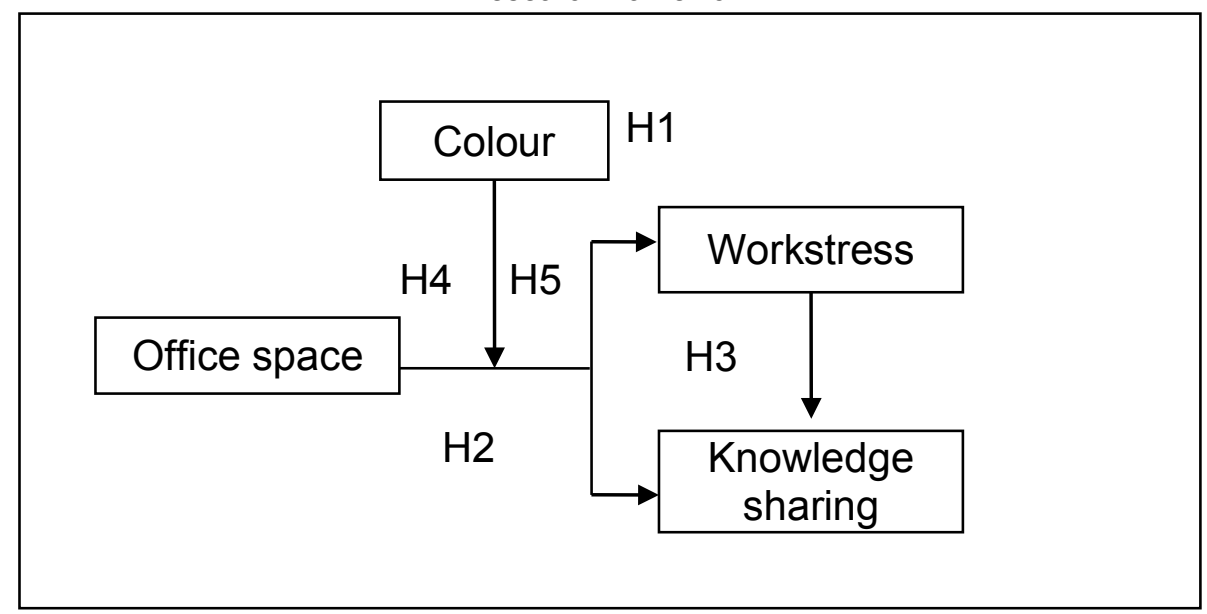

\subsection{Research tool and samples}

The domestic technology industry was selected as the research subject. With purposive sampling, the reliability of the questionnaire pretest reached 839. Questionnaires were distributed to a total of 14 technology companies in Hsinchu Science Park and Southern Taiwan Science Park. Of the 368 copies collected, 21 questionnaires were removed, leaving 347 valid copies.

\subsection{Factor and reliability analyses}

The research dimensions in this study were Office Space, Colour, Work Stress and Knowledge Sharing Intention, and construct validity was tested with the aid of factor analysis. With the aid of principal component factor analysis and the Varimax rotated solution, the major factors were extracted, where Spaciousness, Initiative, and Public Space were the factors in Office Space, with the accumulated variance explaining 78.651 per cent. Two questions on Brightness and Saturation were included under Colour. Work Load, Role Conflict and Role Ambiguity were the factors in Work Stress, with the accumulated variance reported as 67.380 per cent. The variance explanation of
Knowledge Sharing Intention was 67.493 per cent, after factor analysis (Varimax rotated solution). Cronbach's $\alpha$ was further applied to the reliability analysis for an overall reliability $\alpha=845$, and the questionnaire design was found to be favourable.

\section{Analysis 1}

This study covered the four dimensions of Office Space, Colour, Work Stress, and Knowledge Sharing Intention with nine variables of Spaciousness, Initiative, Public Space, Work Load, Role Ambiguity, Role Conflict, Knowledge Sharing Intention, Brightness, and Saturation. The Pearson product-moment correlation analysis was used to test the dimensions; the correlations among the variables are listed in Table 1.

\section{Analysis of effects among dimensions}

Theoretically, Office Space, Colour and Work Stress were multiple compositions and Hierarchical Regression Analysis was utilised to test the correlations among the variables. Regarding the moderating effect of Colour, Hierarchical Regression Analysis, as suggested by Wang (2002), was applied to test the hypotheses. 


\section{Effects of office space on work stress}

With Work Load as the dependent variable and when controlling the demographic variables, $\Delta \mathrm{R}^{2}=.023$ and $\mathrm{P}>.05$, Table 2, Model II, showed no notable relations between Office Space (Spaciousness, Initiative, Public Space) and Work Load.

Table 1

Pearson correlation coefficients of the research variables

\begin{tabular}{|c|c|c|c|c|c|c|c|c|c|c|c|}
\hline & Mean & $\begin{array}{l}\text { Standard } \\
\text { deviation }\end{array}$ & 1 & 2 & 3 & 4 & 5 & 6 & 7 & 8 & 9 \\
\hline 1 Spaciousness & 3.0528 & .97435 & \multicolumn{2}{|c|}{ (.773) } & & & & & & & \\
\hline 2 Initiative & 3.1124 & 1.14563 & $.391^{\prime \prime}$ & \multicolumn{2}{|c|}{$(.801)$} & & & & & & \\
\hline 3 Public space & 3.7594 & 1.18962 & $.299^{\prime \prime}$ & $.238^{\prime \prime}$ & \multicolumn{2}{|c|}{$(.829)$} & & & & & \\
\hline 4 Work load & 3.9316 & .67535 & $.119^{*}$ & .072 & $.156^{\prime \prime *}$ & \multicolumn{2}{|c|}{$(.775)$} & & & & \\
\hline 5 Role ambiguity & 2.5000 & .82676 & $-.254^{\prime \prime}$ & $-.118^{*}$ & $-.275^{N \times}$ & $-.309^{\prime \prime}$ & \multicolumn{2}{|c|}{ (.620) } & & & \\
\hline 6 Role conflict & 3.2594 & .88933 & .091 & $.148^{* \prime}$ & .022 & $.126^{\circ}$ & .073 & \multicolumn{2}{|c|}{$(.593)$} & & \\
\hline $\begin{array}{l}7 \text { Knowledge } \\
\text { sharing Intention }\end{array}$ & 4.0304 & .67136 & -.027 & $.149^{* *}$ & $.190^{* *}$ & $.271^{* *}$ & $-.259^{* *}$ & $-.143^{* *}$ & \multicolumn{2}{|c|}{$(.946)$} & \\
\hline 8 Brightness & .6513 & .47725 & $.367^{\prime \prime}$ & $.281^{\prime \prime}$ & $.295^{\prime \prime}$ & $.148^{\prime \prime}$ & $-.293^{m \prime}$ & .074 & $.118^{\circ}$ & & \multirow{2}{*}{ (.639) } \\
\hline 9 Saturation & .5014 & .50072 & $.271^{\prime \prime}$ & $.292^{*}$ & $.223^{* \prime}$ & -.044 & -.028 & $.171^{*}$ & -.044 & $.298^{* \prime}$ & \\
\hline
\end{tabular}

Table 2, Model II, shows that the correlations between Role Ambiguity and Office Space achieved statistical significance $\left(\Delta \mathrm{R}^{2}=.092\right.$, $\mathrm{P}<.05$ ), with Role Ambiguity as the dependent variable and the demographic variables being controlled. Role Ambiguity and Spaciousness demonstrated negative relations with Public Space $(\beta=-.176, \beta=-.212, \mathrm{P}<.05)$. The Initiatives did not achieve statistical significance $(\beta=.004$, $\mathrm{P}>$.05).
When Role Conflict was treated as the dependent variable and the demographic variables were controlled, the correlations between Role Conflict and Office Space reached statistical significance $\left(\Delta \mathrm{R}^{2}=.023\right.$, $\mathrm{P}<.05)$. Role Conflict and the Initiatives revealed notably positive relations $(\beta=.130$, $\mathrm{P}<.05$ ) but Spaciousness and Public Spaces did not achieve statistical significance $(\beta=.051$, $\beta=-.016, P>.05$ ) for Table 2, Model II.

Table 2

Regression analysis of office space and work stress

\begin{tabular}{|c|c|c|c|c|c|c|}
\hline \multirow{2}{*}{$\begin{array}{l}\text { Dependent variable } \\
\text { Independent variable }\end{array}$} & \multicolumn{2}{|c|}{ Work load } & \multicolumn{2}{|c|}{ Role ambiguity } & \multicolumn{2}{|c|}{ Role conflict } \\
\hline & Model I & Model II & Model I & Model II & Model I & Model II \\
\hline Control variable & $\beta$ & $\beta$ & $\beta$ & $\beta$ & $\beta$ & $\beta$ \\
\hline Gender & -.073 & -.054 & .024 & -.020 & -.039 & -.036 \\
\hline Age & -.017 & -.009 & .048 & .029 & -.020 & -.009 \\
\hline Top education & .094 & .075 & -.177 & -.131 & -.090 & -.087 \\
\hline Work experience & -.024 & -.032 & -.113 & -.101 & .007 & -.016 \\
\hline \multicolumn{7}{|l|}{ Predictionvariable } \\
\hline Spaciousness & & .059 & & $-.176^{* *}$ & & .051 \\
\hline Initiative & & .034 & & .004 & & $.130^{*}$ \\
\hline Public Space & & .107 & & $-.212^{\mathrm{xN*}}$ & & -.016 \\
\hline $\mathrm{R}^{2}$ & .020 & .043 & .037 & .129 & .008 & .031 \\
\hline Adj $R^{2}$ & .009 & .023 & .025 & .111 & -.003 & .011 \\
\hline$\Delta \mathrm{F}$ & 1.780 & 2.632 & 3.259 & $11.943^{* * *}$ & .703 & $2.687^{*}$ \\
\hline Sig.of $F$ & .0132 & $.050^{*}$ & .012 & .000 & .590 & .046 \\
\hline
\end{tabular}




\section{Effects of office space on knowledge} sharing

A Knowledge Sharing Intention can be a dependent variable and the demographic variables can be controlled. The correlations between Office Space and Knowledge Sharing showed statistical significance $\left(\Delta \mathrm{R}^{2}=.063\right.$,
$\mathrm{P}<.05)$, where Initiative, Public Space and Knowledge Sharing Intention showed remarkably positive relations $(\beta=.152, \beta=.199$, $\mathrm{P}<.01$ ), but Spaciousness and Knowledge Sharing Intention exhibited significantly negative relations $(\beta=-.129, \mathrm{P}<.05)$ in Table 3 , Model II.

Table 3

Regression analysis of office space and knowledge sharing intention

\begin{tabular}{|l|c|c|}
\hline \multicolumn{1}{|c|}{ Dependent variable } & Knowledge sharing intention \\
\hline Independent variable & Model I & Model II \\
\hline Control variable & $\beta$ & $\beta$ \\
\hline Gender & .010 & .021 \\
\hline Age & .261 & .255 \\
\hline Highest education & .024 & .017 \\
\hline Work experience & -.067 & -.069 \\
\hline Prediction variable & & \\
\hline Spaciousness & &. $.129^{*}$ \\
\hline Initiative & & $.152^{* *}$ \\
\hline Public Space & & $.199^{* * *}$ \\
\hline$R^{2}$ & .052 & .115 \\
\hline Adj $R^{2}$ & .041 & .096 \\
\hline$\Delta \mathrm{F}$ & $4.693^{* *}$ & $7.933^{* * *}$ \\
\hline Sig.of $F$ & .001 & .000 \\
\hline Note: ${ }^{*} \mathrm{p}<.05,{ }^{* *} \mathrm{p}<.01,{ }^{* * *} \mathrm{p}<.001$. & & \\
\hline
\end{tabular}

3 Effects of work stress on knowledge sharing

With the Knowledge Sharing Intention as the dependent variable and when the demographic variables were controlled, the correlations between Work Stress and Knowledge Sharing achieved statistical significance $\left(\Delta \mathrm{R}^{2}=.141\right.$, $\mathrm{P}<.001)$. Work Load and Knowledge Sharing Intention showed remarkably positive relations $(\beta=.250, P<.001)$, but Role Ambiguity, Role Conflict and Knowledge Sharing Intention presented notably negative relations $(\beta=-.186$, $\beta=-.163, P<.001)$, as shown in Table 4, Model II.

\section{Moderating effects of colour on the relations between office space and work stress}

With Work Load as the dependent variable and when the demographic variables were controlled, Colour (low saturation and low brightness, high saturation and low brightness, low saturation and high brightness) did not display moderating effects on the relations between
Office Space and Work Load, and no statistical significance $\left(\Delta \mathrm{R}^{2}=-.016, \Delta \mathrm{R}^{2}=.215, \Delta \mathrm{R}^{2}=.063\right.$, $\mathrm{P}>.05)$ was recorded. The moderating effects of Colour (high saturation and high brightness) on the relations between Office Space and Work Load revealed statistical significance $\left(\Delta \mathrm{R}^{2}=.076, \mathrm{P}<.05\right)$. This is where the Public Space and Work Load displayed significantly positive relations $(\beta=.267, \mathrm{P}<.05)$, while Spaciousness, Initiative and Work Load did not reach statistical significance $(\beta=.043$, $\beta=.010, P>.05)$ as shown in Table 5, Model II.

With Role Ambiguity as the dependent variable and when the demographic variables were controlled, the moderating effects of Colour (low saturation and low brightness) on the relations between Office Space and Role Ambiguity did not achieve statistical significance $\left(\Delta \mathrm{R}^{2}=.005, \mathrm{P}>.05\right)$. The moderating effects of Colour (high saturation and low brightness) on the relations between Office Space and Role Ambiguity showed statistical significance $\left(\Delta \mathrm{R}^{2}=.318, \mathrm{P}<.05\right)$, where Public 
Space and Role Ambiguity displayed notably positive relations $(\beta=.107, \quad \mathrm{P}<.05)$. The moderating effects of Colour (low saturation and high brightness) on the relations between Office Space and Role Ambiguity reached statistical significance $\left(\Delta \mathrm{R}^{2}=.061, \quad \mathrm{P}<.05\right)$ where Spaciousness and Role Ambiguity presented remarkably negative relations $(\beta=-$ $.276, \mathrm{P}<.05$ ), but Office Space (Initiative, Public Space) and Role Ambiguity did not achieve statistical significance $(\beta=-.020, \beta=-$ $.220, \mathrm{P}>.05$ ), as shown in Table 6 , Model II.

Table 4

Regression analysis of work stress and knowledge sharing intention

\begin{tabular}{|c|c|c|}
\hline Dependent variable & \multicolumn{2}{|c|}{ Knowledge sharing intention } \\
\hline Independent variable & Model I & Model II \\
\hline Control variable & $\beta$ & $\beta$ \\
\hline Gender & .010 & .027 \\
\hline Age & .261 & .271 \\
\hline Highest education & .024 & -.048 \\
\hline Work experience & -.067 & -.084 \\
\hline \multicolumn{3}{|l|}{ Prediction variable } \\
\hline Work Load & & $.250^{\mathrm{x*x}}$ \\
\hline Role Ambiguity & & $-.186^{\mathrm{xNx}}$ \\
\hline Role Conflict & & $-.163^{* x}$ \\
\hline $\mathrm{R}^{2}$ & .052 & .193 \\
\hline Adj $R^{2}$ & .041 & .176 \\
\hline$\Delta \mathrm{F}$ & $4.693^{* *}$ & $19.501^{* * *}$ \\
\hline Sig.of $F$ & .001 & .000 \\
\hline
\end{tabular}

Table 5

Regression analysis of the moderating effects of Colour on the relations between Office Space and Work Stress (Work Load)

\begin{tabular}{|c|c|c|c|c|c|c|c|c|}
\hline \multirow{3}{*}{$\begin{array}{l}\text { Dependent variable } \\
\text { Independent variable }\end{array}$} & \multicolumn{2}{|c|}{$\begin{array}{l}\text { Low saturation and } \\
\text { low brightness }\end{array}$} & \multicolumn{2}{|c|}{$\begin{array}{l}\text { High saturation and } \\
\text { low brightness }\end{array}$} & \multicolumn{2}{|c|}{$\begin{array}{l}\text { Low saturation and } \\
\text { high brightness }\end{array}$} & \multicolumn{2}{|c|}{$\begin{array}{l}\text { High saturation and } \\
\text { high brightness }\end{array}$} \\
\hline & \multicolumn{8}{|c|}{ Work Load } \\
\hline & Model I & Model II & Model I & Model II & Model I & Model II & Model I & Model II \\
\hline Control variable & $\beta$ & $\beta$ & $\beta$ & $\beta$ & $\beta$ & $\beta$ & $\beta$ & $\beta$ \\
\hline Gender & .077 & .082 & .173 & .343 & -.290 & -.329 & -.097 & -.150 \\
\hline Age & -.053 & -.037 & -.127 & .024 & -.169 & -.061 & .097 & .064 \\
\hline Highest education & .186 & .216 & .036 & .131 & -.071 & -.130 & .127 & .086 \\
\hline Work experience & .017 & .031 & .255 & .158 & .096 & .028 & -.159 & -.112 \\
\hline \multicolumn{9}{|l|}{ Prediction variable } \\
\hline Spaciousness & & -.092 & & .407 & & .104 & & .043 \\
\hline Initiative & & -.078 & & .055 & & .239 & & .010 \\
\hline Public Space & & .018 & & .176 & & .036 & & $.267^{x \pi}$ \\
\hline $\mathrm{R}^{2}$ & .037 & .053 & .059 & .274 & .077 & .140 & .056 & .132 \\
\hline Adj $R^{2}$ & -.011 & -.033 & -.062 & .093 & .033 & .064 & .027 & .085 \\
\hline$\Delta \mathrm{F}$ & .762 & .452 & .487 & 2.769 & 1.734 & 1.933 & 1.961 & 3.795 \\
\hline Sig.of F & .553 & .716 & .745 & .060 & .150 & .131 & .104 & $.012^{\mathrm{xx}}$ \\
\hline
\end{tabular}


With Role Conflict as the dependent variable and by controlling the demographic variables, the moderating effects of Colour (low saturation and low brightness, high saturation and low brightness, low saturation and high brightness, high saturation and high brightness) on the relations between Office Space and Role Conflict did not show statistical significance $\left(\Delta \mathrm{R}^{2}=-.033, \Delta \mathrm{R}^{2}=.007, \Delta \mathrm{R}^{2}=.051\right.$, $\left.\Delta \mathrm{R}^{2}=-.038, \mathrm{P}>.05\right)$, as shown in Table 7 , Model II.

Table 6

Regression analysis of the moderating effects of Colour on the relations between Office Space and Work Stress (Role Ambiguity)

\begin{tabular}{|c|c|c|c|c|c|c|c|c|}
\hline \multirow{3}{*}{$\begin{array}{c}\text { Colour } \\
\text { Dependent variable } \\
\text { Independent variable }\end{array}$} & \multicolumn{2}{|c|}{$\begin{array}{l}\text { Low saturation and } \\
\text { low brightness }\end{array}$} & \multicolumn{2}{|c|}{$\begin{array}{l}\text { High saturation and } \\
\text { low brightness }\end{array}$} & \multicolumn{2}{|c|}{$\begin{array}{l}\text { Low saturation and } \\
\text { high brightness }\end{array}$} & \multicolumn{2}{|c|}{$\begin{array}{l}\text { High saturation and } \\
\text { high brightness }\end{array}$} \\
\hline & \multicolumn{8}{|c|}{ Role Ambiguity } \\
\hline & Model I & Model II & Model I & Model II & Model I & Model II & Model I & Model II \\
\hline Control variable & $\beta$ & $\beta$ & $\beta$ & $\beta$ & $\beta$ & $\beta$ & $\beta$ & $\beta$ \\
\hline Gender & .092 & .009 & -.125 & -.344 & .153 & .100 & -.145 & -.119 \\
\hline Age & -.089 & -.119 & .406 & .159 & .038 & -.064 & .037 & .032 \\
\hline Highest education & -.043 & -.078 & .077 & .014 & -.237 & -.136 & -.272 & -.221 \\
\hline Work experience & -.199 & -.226 & -.351 & -.154 & -.071 & -.005 & -.013 & -.021 \\
\hline \multicolumn{9}{|l|}{ Prediction variable } \\
\hline Spaciousness & & .181 & & -.368 & & $\underline{-.276^{*}}$ & & $\underline{-.204^{*}}$ \\
\hline Initiative & & -.091 & & -.011 & & .020 & & .060 \\
\hline Public Space & & .178 & & $.416^{*}$ & & -.220 & & .127 \\
\hline $\mathrm{R}^{2}$ & .064 & .114 & .083 & .401 & .098 & .205 & .081 & .142 \\
\hline Adj $R^{2}$ & .017 & .033 & -.035 & .251 & .054 & .136 & .054 & .095 \\
\hline$\Delta \mathrm{F}$ & 1.367 & 1.438 & .701 & 4.957 & 2.247 & 3.607 & 2.944 & 3.040 \\
\hline Sig.of $F$ & .253 & .238 & .597 & $.007^{* *}$ & .071 & $.017^{\pi x}$ & $.023^{x}$ & $.031^{* *}$ \\
\hline
\end{tabular}

Table 7

Regression analysis of the moderating effects of Colour on the relations between Office Space and Work Stress (Role Conflict)

\begin{tabular}{|c|c|c|c|c|c|c|c|c|}
\hline \multirow{3}{*}{$\begin{array}{c}\text { Colour } \\
\text { Dependent variable } \\
\text { Independent variable }\end{array}$} & \multicolumn{2}{|c|}{$\begin{array}{l}\text { Low saturation and } \\
\text { low brightness }\end{array}$} & \multicolumn{2}{|c|}{$\begin{array}{l}\text { High saturation and } \\
\text { low brightness }\end{array}$} & \multicolumn{2}{|c|}{$\begin{array}{l}\text { Low saturation and } \\
\text { high brightness }\end{array}$} & \multicolumn{2}{|c|}{$\begin{array}{l}\text { High saturation and } \\
\text { high brightness }\end{array}$} \\
\hline & \multicolumn{8}{|c|}{ Role Conflict } \\
\hline & Model I & Model II & Model I & Model II & Model I & Model II & Model I & Model II \\
\hline Control variable & $\beta$ & $\beta$ & $\beta$ & $\beta$ & $\beta$ & $\beta$ & $\beta$ & $\beta$ \\
\hline Gender & .058 & -.014 & -.337 & -.290 & -.171 & -.234 & .032 & .028 \\
\hline Age & .053 & .028 & -.275 & -.284 & -.098 & -.120 & -.016 & -.009 \\
\hline Highest education & -.106 & -.140 & .200 & .285 & -.367 & -.411 & .071 & .089 \\
\hline Work experience & -.196 & -.239 & -.052 & -.011 & .163 & .174 & .048 & .022 \\
\hline \multicolumn{9}{|l|}{ Prediction variable } \\
\hline Spaciousness & & .123 & & .264 & & -.144 & & .087 \\
\hline Initiative & & .043 & & .076 & & .168 & & .149 \\
\hline Public Space & & .180 & & .131 & & .086 & & .025 \\
\hline $\mathrm{R}^{2}$ & .041 & .074 & .262 & .332 & .130 & .181 & .007 & .045 \\
\hline Adj $R^{2}$ & -.007 & -.010 & .167 & .165 & .088 & .109 & -.023 & -.006 \\
\hline$\Delta \mathrm{F}$ & .862 & .910 & 2.758 & .972 & 3.110 & 1.648 & .221 & 1.763 \\
\hline Sig. of F & .490 & .440 & .045 & .420 & .019 & .185 & .926 & .157 \\
\hline
\end{tabular}


5 Moderating effect of colour on the relations between office space and knowledge sharing

Taking Knowledge Sharing Intention as the dependent variable and when controlling the demographic variables, the moderating effects of Colour (low saturation and low brightness, high saturation and low brightness, low saturation and high brightness) on the relations between Office Space and Work Load did not reach statistical significance $\left(\Delta \mathrm{R}^{2}=. .145\right.$, $\left.\Delta \mathrm{R}^{2}=.100, \Delta \mathrm{R}^{2}=.064, \mathrm{P}>.05\right)$. The moderating effects of Colour (high saturation and high brightness) on the relations between Office Space and Knowledge Sharing Intention achieved statistical significance $\left(\Delta \mathrm{R}^{2}=.079, \quad \mathrm{P}<.05\right)$. There were significantly negative relations between Office Space (Spaciousness) and Knowledge Sharing Intention $(\beta=-.203, \mathrm{P}<.05)$, but remarkably positive relations between Office Space (Initiative, Public Space) and Knowledge Sharing Intention $(\beta=.209, \beta=.234$, $\mathrm{P}<.05$ ), as shown by Table 8 , Model II.

Table 8

Regression analysis of the moderating effects of Colour on the relations between Office Space and Knowledge Sharing

\begin{tabular}{|c|c|c|c|c|c|c|c|c|}
\hline \multirow{3}{*}{\begin{tabular}{l}
\multicolumn{1}{c}{ Colour } \\
Dependent variable \\
Independent \\
variable
\end{tabular}} & \multicolumn{2}{|c|}{$\begin{array}{l}\text { Low saturation and } \\
\text { low brightness }\end{array}$} & \multicolumn{2}{|c|}{$\begin{array}{l}\text { High saturation and } \\
\text { low brightness }\end{array}$} & \multicolumn{2}{|c|}{$\begin{array}{l}\text { Low saturation and } \\
\text { high brightness }\end{array}$} & \multicolumn{2}{|c|}{$\begin{array}{l}\text { High saturation and } \\
\text { high brightness }\end{array}$} \\
\hline & \multicolumn{8}{|c|}{ Knowledge sharing intention } \\
\hline & Model I & Model II & Model I & Model II & Model I & Model II & Model I & Model II \\
\hline Control variable & $\beta$ & $\beta$ & $\beta$ & $\beta$ & $\beta$ & $\beta$ & $\beta$ & $\beta$ \\
\hline Gender & -.086 & .005 & .378 & .512 & .023 & -.033 & -.011 & -.055 \\
\hline Age & .374 & .397 & .257 & .438 & -.046 & -.108 & .298 & .241 \\
\hline Highest education & .102 & .126 & .147 & .153 & .115 & .060 & -.109 & -.083 \\
\hline Work experience & -.008 & .027 & .239 & .095 & .006 & .042 & -.146 & -.099 \\
\hline \multicolumn{9}{|l|}{ Prediction variable } \\
\hline Spaciousness & & -.128 & & .180 & & -.192 & & $-.203^{*}$ \\
\hline Initiative & & .070 & & -.083 & & .108 & & $.209^{*}$ \\
\hline Public Space & & .208 & & .305 & & .152 & & $.234^{* *}$ \\
\hline $\mathrm{R}^{2}$ & .062 & .207 & .362 & .462 & .016 & .080 & .073 & .152 \\
\hline Adj $R^{2}$ & .120 & .135 & .280 & .327 & -.032 & .000 & .044 & .106 \\
\hline$\Delta \mathrm{F}$ & 3.854 . & 1.473 & 4.403 & 1.724 & .331 & 1.865 & 2.571 & 3.980 \\
\hline Sig.of $F$ & $.006^{* *}$ & .228 & $.006^{\text {"* }}$ & .185 & .856 & .142 & $.041^{*}$ & $.009^{* "}$ \\
\hline
\end{tabular}

\section{5}

\section{Conclusions and suggestions}

To sum up the research results, the findings were as follows: 1. Spaciousness and public space in the office space reveal notably negative correlations with Role Ambiguity, which indicates that the larger office and public spaces could reduce Role Ambiguity. 2. Spaciousness and Initiative in the office and public spaces showed remarkable effects on Knowledge Sharing Intention, with Initiative and public space revealing significantly positive correlations. This shows that the higher the initiatives in space design, the higher the Knowledge Sharing Intention. 3. Work Load, Role Ambiguity and Role Conflict in Work Stress displayed outstanding effects on Knowledge Sharing Intention, with Work Load showing notably positive correlations. It also reflected a heavier Work Load and higher Knowledge Sharing Intention. 4. Colour (high saturation and high brightness) revealed remarkably positive moderating effects on the relations between Office and Public Space and Work Load. Colour (high saturation and low brightness) showed notably positive moderating effects on the relations between Office and Public Space and Role Ambiguity. Colour (low saturation and high brightness, high saturation 
and high brightness) displayed notably negative moderating effects on the relations between Spaciousness and Role Ambiguity. Accordingly, the following suggestions are made: 1. Although the factors in space allocation depend on the size of the individual space, a larger office could effectively reduce Role Ambiguity, and Office Space with higher Initiative displays higher Role Conflict. In this case, high-technology businesses should employ broader and open office space designs to effectively reduce their employees' Work Stress. Another research outcome indicated that a broader space is unfavourable for Knowledge Sharing Intention. Businesses therefore have to consider the degree of Knowledge Sharing between the staff and balance the two conclusions to achieve optimal space planning without pushing up costs unnecessarily. with regard to the creation of Public Space, the findings showed that a larger Public Space was able to reduce Role Ambiguity and could be preference for a hightechnology industry. 2. Colour shows significant moderating effects on Work Stress and Knowledge Sharing, and different combinations of chroma and brightness reveal distinct effects on Work Stress and Knowledge Sharing. Businesses should therefore consult with interior designers when planning colour for the office. In conclusion, a high-chroma space could not effectively reduce Work Stress, while a high-brightness space could. Moreover, the chroma and the brightness of Colour appear to have lower effects on Knowledge Sharing, but a space with high brightness and high chroma could affect Knowledge Sharing Intention. 3. Work Stress shows remarkable effects on knowledge sharing intention. A higher Work Load could benefit from Knowledge Sharing, but not Role Ambiguity and Role Conflict. For this reason, a high-technology industry needs its staff to generate favourable Knowledge Sharing Intention under moderate Work Stress. In contrast, Knowledge Sharing Intention could be enhanced by reducing the employees' Role Ambiguity and Role Conflict. 4. The infrastructure of Knowledge Sharing is a key factor in Knowledge Sharing Intention. The research findings show that the Public Space in the office could effectively promote Knowledge Sharing Intention, which indicates the importance of an office of the Public Space. Such a conclusion further supports the need for organisations to provide an interactive space and venues for interaction by employees. It is believed that this study could enhance the emphasis of the high-technology industry on the establishment office of the Public Space.

\section{Acknowledgement}

The authors are grateful to the valuable comments made by the reviewers.

*CORRESPONDING AUTHOR CONTACT

Yu-Lan Wang, yulan.duker@gmail.com

\section{References}

ANONYMOUS. 2003. Design to Work? New Zealand Management, Oct:56.

CHANG, H. 1995. Architectural and environmental psychology. Garden City Press:285-292.

CHEN, P. 2004. Relations among work value, work motivation, and knowledge-sharing behaviors-A study on employees of hi-tech industries in Taiwan. College of Management, National Taiwan University.

CHANG, T. \& HAN, Y. 2006. Color psychological effect in interior environment. Journal of Qingdao Technological University, 27(6):18.

CHIANG, M. 2000. Vision and knowledge management of non-profit making organizations, Conference for NPO chief executives. Organizational Strategies:57-59.

CHIU, HSIN-HSIEN. 1994. Relations among work characters, personality traits, role stress, and the intentions of work stress, job satisfaction, and resignation. Department of Business Administration, National Chung Hsing University.

CHIU, M. 2012. Color preferences for office spaces: Interior Design. College of Design, Chung Yuan Christian University. 
DENG, H. \& WENG, C. 1991. Study of color. Cheng Wen Books, 14.

DOWNEY, L. 2004. Making workplaces fit. Corporate Report Wisconsin, 20(1):40-46.

GRANT, R.M. 1996. Toward a knowledge-based theory of the firm. Strategic Management Journal, 17:109122.

HARRAR, S. 1999. Hidden job stress can raise blood pressure. Prevention, 51(5):42-55.

HANSON, M.T. 2002. Knowledge networks: explaining effective knowledge sharing in multiunit companies. Organization Science, 13(3):232-248.

HEATHER, A.E. 2003. Building a workplace of choice: Using the work environment to attract and retain top talent. Journal of Facilities Management, 2(3):244-257.

HIROSHI, O. 1991. Color planning for design. Talu Publications:264-268.

HOU, W. 1984. Positive research on work stress: organizational climate, role characteristics, personality traits, and stress symptoms. Management Review:38-46.

HUA, L. 2009. The cross level moderating effects of organizational formal and informal mechanisms upon the relationships among promotion focus, knowledge sharing willingness and knowledge sharing behaviors. Business Administration, Providence University.

IVANCEVICH, J.M. \& MATTESON, M.T. 1980. Stress and work: a managerial perspective. NY: Scott Foresman.

KENDALL, K.E. \& KENDALL, J.E. 1981. Observing organizational environments: asystematic approach for information analysts. MIS Quarterly, March:43-55.

ELSBACH, K.D. \& BECHKY, B.A. 2007. It's more than a desk: working smarter through leveraged office design. California Management Review, 49(2):80-98.

KUO, C. 2006. Applications of color rules in interior design. Journal of Hunan City University, 27(2):96-98.

LAI, C. 2001. A study on work performance system and work stress of investigators in the Bureau of Investigation. Executive Master of Public Affairs, Tunghai University.

LAN, TSAI-FENG. 2000. Stress and adaptation, Taipei, Young Lion Press

LEE, L., CHEN, K. \& LAI, C. 2012. The relationships among job stress, leisure participation and wellbeing-a study of laborers of hi-tech industry in Hsinshu Science Park. National Chiao Tung University Journal of Physical Education, 3:40-52.

LIN, N. \& ENSEL, W.M. 1989. Life stress and health: Stressors and resources. American Sociological Review, 54:382-399.

LIN, T. 2005. Knowledge management. Chih Shen Culture, 264.

LIU, S. 2006. The study of knowledge dissemination management - the case of Kaohsiung City Police Department and Kaohsiung Harbor Police Bureau. Postgraduate Programs in Management, I-Shou University.

LIU, C. \& WANG, R. 2009. The relationship of work stress, stress coping, and organizational empowerment to depression of high-tech industry employees. New Taipei Journal of Nursing, 11(2):7-17.

LIU, Y. 2003. A study of leisure activities participating, work pressure, and work fulfillment of rank and file firemen. Graduate School of Leisure and Exercise Studies, National Yunlin University of Science \& Technology.

ROBBINS, S.P. 2001. Organizational behavior. Englewood Cliffs, NJ: Prentice-Hall.

TANG, P., CHEN, Y. \& CHEN, L. 2002. Work stress. Chinese Journal of Occupational Medicine, 9(2):145147.

WANG, C. 2002. Relations among knowledge learning, knowledge diffusion, and work performance-A case study on shipping. Department of Shipping \& Transportation Management, National Taiwan Ocean University.

WANG, C. 1993. Interior design. Taipei: Yifongtan Books. 